\title{
Aerobic Exercise Effects upon Cognition in Mild Cognitive Impairment: a Systematic Review of Randomized Controlled Trials
}

\author{
D.M. CAMMISULI', A. INNOCENTI 1,2, F. FRANZONI ${ }^{3}$, C. PRUNETI',2 \\ ' Department of Medicine and Surgery, Laboratory of Clinical Psychology, University of Parma, Parma, Italy; \\ ${ }^{2}$ Centre of Sport Medicine and Physical Exercise Centre (SEM), University of Parma, Parma, Italy; \\ ${ }^{3}$ Department of Clinical and Experimental Medicine, Sport Medicine Unit, University of Pisa, Pisa, Italy.
}

\begin{abstract}
A B S T R A C T
Several studies have shown that physical activity has positive effects on cognition in healthy older adults without cognitive complains but lesser is known about the effectiveness of aerobic exercise in patients suffering from Mild Cognitive Impairment (MCI). The aim of the present study was to systematically review the evidence from randomized controlled trials (RCTs) about the effects of aerobic exercise upon cognition in MCI patients. To this end, PubMed, Cochrane and Web of Science databases were analytically searched for RCTs including aerobic exercise interventions for MCI patients. There is evidence that aerobic exercise improves cognition in MCI patients. Overall research reported moderate effects for global cognition, logical memory, inhibitory control and divided attention. Due to methodological limitations of the investigated studies, findings should be interpreted with caution. Standardized training protocols, larger scale interventions and follow-ups may also provide better insight into the preventive effects of aerobic exercise on cognitive deterioration in MCI and its conversion into dementia.
\end{abstract}

Key words

Mild cognitive impairment $\bullet$ Aerobic exercise $\bullet$ cognition $\bullet$ Non-pharmacological intervention $\bullet$ Randomized controlled trial

\section{Introduction}

Mild Cognitive Impairment (MCI) depicts a transitional intermediate state between physiological aging and dementia and refers to a clinical syndrome with multiple profiles and different aetiologies (Petersen et al., 2014). The initial definition of MCI directly concerns the detection of underlying Alzheimer's Disease (AD). Originally, amnestic deficit was neuropsychologically thought to be a predictor of $\mathrm{AD}$ in $\mathrm{MCI}$ patients whilst more recent research stated that episodic memory damage along with executive dysfunction represents the main risk factors for MCI conversion into dementia (Cammisuli et al., 2012; Summer and Saunders, 2012). Original MCI criteria were then improved by additional clinical features, genetic background, predictors of progression and pathological outcomes leading to criteria proposed by the National Institute on Aging and the Alzheimer's Association (Albert et al., 2011) and by the Diagnostic and statistical manual of mental disorders fifth edition (DMS-V) (APA, 2013). Recently, a transitional state very similar to MCI in AD has been recognized also in Parkinson's Disease (Geurtsen et al., 2014; Cammisuli \& Timpano, 2017; Hoogland et al., 2017). Cognitive impairment is common in nondemented PD patients in different extent and it is associated with an increasing risk to develop Parkinson's Disease Dementia (Litvan et al., 2012). There is growing evidence that non-pharmacological interventions help in preserving personal and instrumental autonomy, reducing neuropsychiatric symptoms and improving quality of life in $\mathrm{AD}$ 


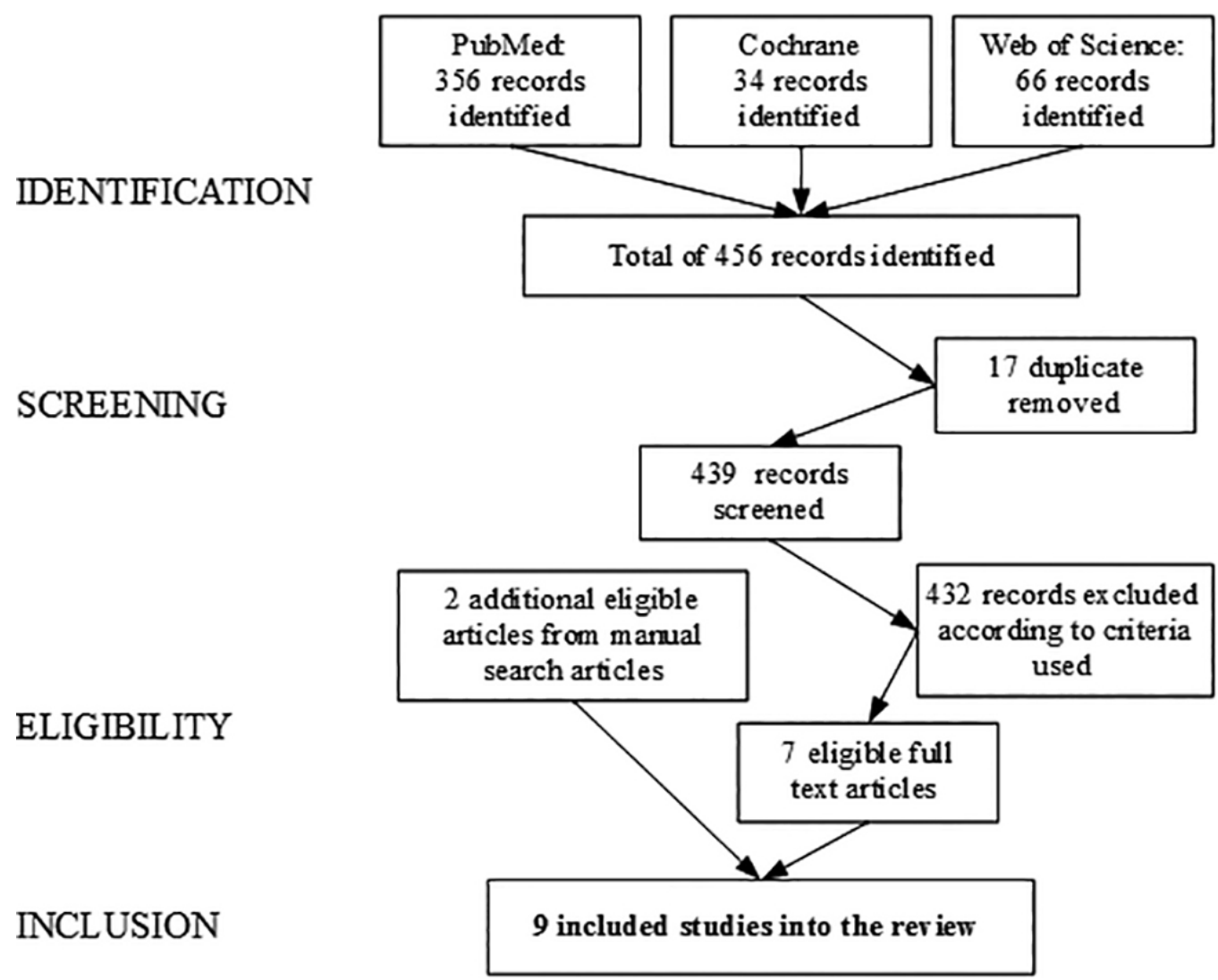

Fig. 1. - Flow diagram: studies selection criteria.

patients (Graessel et al., 2011; Tsolaki, 2016; Cipriani et al., 2016; Cammisuli et al., 2016). Cognitive training for MCI and mild AD has been found to be effective in ameliorating patients' residual cognitive abilities and reducing caregivers' burden (Cammisuli et al., 2011; Bergamaschi et al., 2013). Moreover, an evolving literature has shown significant benefits of physical exercise, specifically aerobic one, in attenuating cognitive impairment and reducing dementia progression (Ahlskog et al., 2011).

Cognitive functionality of MCI patients can take advantage from regular physical exercise, in particular for executive functioning sustaining patients' personal and instrumental autonomy of daily living (Farina et al., 2014). Aerobic activity is a physical exercise of low to high intensity that depends mainly on the aerobic energy generating process, referring to the use of oxygen to adequately meet energy demands during exercise. Generally, it involves any exercise that increases heart rate and keeps it higher than basal one for extended periods of time. Aerobic exercises like walking, running, swimming, aquarobics, cycling, rowing, etc., improve vascular health, reduce blood pressure, arterial stiffness, oxidative stress, systemic inflammation and enhance endothelial function (Forbes et al., 2013).

MCI patients present with brain alterations preceding many times before the onset of overt AD (De Carli et al, 2007; Pike et al., 2007). A large amount of experimental studies showed potential mechanisms to account for cognition improvement due to exercise including effects on neuronal survivability and function, neuroinflammation, vascularization, neuroendocrine response to stress and brain amyloid burden, and on physiological processes, such as glucoregulation and cardiovascular system (Baker et al., 2010). In humans, brain imaging studies suggested that aerobic fitness in heathy elderly is associated with reduced age-related atrophy and increased perfusion in brain areas sustaining executive functions and memory that resulted as vulnerable to aging effects (Baker et al., 2010).

Previous meta-analyses of RCTs showed that physical exercise in healthy adults is associated to cognitive improvement, larger hippocampal volumes, attenuation of age-related grey matter 


\begin{tabular}{|c|c|c|c|c|}
\hline Tab. 1. - Evaluation of selection criteria of included studies. \\
\hline Study & 1 & 2 & 3 & 4 \\
\hline Scherder et al., 2005 & + & $+/-$ & - & $+/-$ \\
\hline Lautenschlager et al., 2008 & - & + & + & + \\
\hline van Uffelen et al., 2009 & - & + & + & + \\
\hline Baker et al., 2010 & + & + & + & + \\
\hline Valera et al., 2012 & $+/-$ & $+/-$ & + & + \\
\hline Suzuki et al., 2012 & + & + & + & + \\
\hline Suzuki et al., 2013 & + & + & + & + \\
\hline Nagamatsu et al., 2013 & - & + & + & + \\
\hline
\end{tabular}

\begin{tabular}{|c|c|c|c|c|c|c|c|}
\hline Study & $\begin{array}{l}\text { Selection } \\
\text { bias }\end{array}$ & $\begin{array}{l}\text { Study } \\
\text { design }\end{array}$ & Confounders & Blinding & $\begin{array}{c}\text { Data } \\
\text { collection }\end{array}$ & Withdrawal & Overall \\
\hline Scherder et al., 2005 & $* * *$ & $* *$ & $* *$ & $* * *$ & $* * *$ & $*$ & $* *$ \\
\hline Lautenschlager et al., 2008 & $* * *$ & $* * *$ & $* * *$ & $* * *$ & $* * *$ & $* *$ & $* * *$ \\
\hline van Uffelen et al., 2009 & $* * *$ & $* * *$ & $* * *$ & $* * *$ & $* * *$ & $* * *$ & $* * *$ \\
\hline Baker et al., 2010 & $* * *$ & $* * *$ & $* * *$ & ** & $* * *$ & $* *$ & $* * *$ \\
\hline Valera et al., 2012 & $* * *$ & $* * *$ & * & $* *$ & * & * & $* *$ \\
\hline Suzuki et al., 2012 & $* * *$ & $* * *$ & $* *$ & * & $* * *$ & * & $* *$ \\
\hline Suzuki et al., 2013 & $* * *$ & $* * *$ & $*$ & $* *$ & $* * *$ & * & $* *$ \\
\hline Nagamatsu et al., 2013 & * & $* * *$ & $*$ & $* *$ & $* * *$ & $* * *$ & $* *$ \\
\hline Davis et al., 2013 & * & $* * *$ & * & * & * & $* *$ & * \\
\hline
\end{tabular}

volume loss, and improved connectivity of brain networks (Ahlskog et al., 2011). The aim of this study was to systematically review the evidence from randomized controlled trials (RCTs) about the specific effects of aerobic exercise on cognition in MCI patients and to suggest prescriptions for a routinely healthy lifestyle to follow.

\section{Methods}

PubMed (general search without any restriction), Cochrane Library (search 'All text') and Web of Science (search as 'Topic') databases were systematically examined for RCTs using the following terms in: "mild cognitive impairment" AND "aerobic exercise" AND "cognition". The search was performed on December 2016 and repeated on March 2017. Additional titles were manually searched in relevant bibliographies of previous studies on the investigated topic (Smith et al., 2010; Ahlskog et al., 2011; Gates et al., 2013; Öhman et al., 2014; Zheng et al., 2016).

The studies from the literature search were selected from initial search if the met the following criteria: (1) patients with MCI; (2) aerobic exercise as one of the main interventions (multicomponent interventions were potentially eligible for inclusion if they included aerobic exercise as principal practice; indeed, combined programs of different physical exercises may induce specific brain changes); (3) randomized controlled trial as study design; (4) any validate neuropsychological test of cognition reported at baseline and at follow-up. 
Exclusion criteria included: (1) studies recruiting individuals with neurological diseases different from MCI (i.e., Alzheimer's disease or other dementias, stroke, multiple sclerosis, traumatic brain injury, Parkinson's Disease, focal brain disorders, etc.) individuals with subjective cognitive decline, subjects with age-related cognitive decline or unspecified memory complaints, psychiatric diseases and other comorbid medical conditions (e.g., mild cognitive impairment and diabetes mellitus); (2) aerobic exercise as sport practice (e.g., Thai Chi, handball, etc.); (3) manuscripts written in other languages than English. This screening finally yielded 9 studies to be evaluated (Figure 1).

Three independent reviewers (D.M.C., A.I., and C.P.) evaluated the included studies for methodological quality (Table 1). Disagreement was discussed until a consensus was definitively reached. Methodological quality of the selected manuscripts was checked by criteria for RCTs used by Cochrane (Forbes et al. 2008). To ascertain the validity of eligible randomized trials, a pair of reviewers (D.M.C. and F.F.) working independently and with adequate reliability assessed the risk of bias in relation to selection, study design, confounders, blinding, data collection and withdrawal using the Quality Assessment Tool for Quantitative Studies (Thomas et al., 2004) (Table 2).

\section{Results}

Overall, the quality of included trials was moderate. Results from nine studies selected are summarized in Table 3. Eight studies used Mini Mental State Examination (MMSE) (Folstein et al., 1975) to examine the effect of aerobic exercise on global cognition whilst only one study used Alzheimer's Disease Assessment Scale-Cognitive Subscale (ADAS-cog) (Rosen et al. 1984). Montreal Cognitive Assessment (MoCA) (Nasreddine et al., 2005) came up beside these global screening instruments in two studies. MMSE is widely used in clinical practice but it is less informative than MoCA, so that it has a limited power due to poorer psychometric properties. Nevertheless, three studies reported improvement in global cognition after intervention by the MMSE. We noted that only some specific executive subdomains improved after an aerobic intervention. Researchers usually moved to evaluate few cognitive functions associated to dorsolateral prefrontal cortex and anterior cingulate cortex by fluency tests, Stroop test and dual-task conditions (i.e., TMT), that have been observed to be poor in MCI patients (Cammisuli et al., 2013). Starting from this assumption, we have to limit results to improvements in inhibitory control and divided attention only. However, our research replicates previous findings on healthy elderly subjects undergone physical trainings (Colcombe and Kramer, 2003; Hillman et al., 2008; Pruneti et al., 2017) but they are little surprising in relation to memory enhancement. Indeed, three selected studies (Suzuki et al., 2012, 2013; Nagamatsu et al., 2013) reported that aerobic exercise may boost long-term memory under a free recall condition. Again, this could be due to the role of executive functions in organizing and making meaningful verbal material after experimenter's test presentation of prose story that allows long and cohesive responses of the examinees (cfr. Cammisuli and Timpano Sportiello, 2016).

\section{Summary}

On the basis of the present findings, we prudently state that MCI patients benefit from aerobic exercise but we cannot conclude that aerobic exercise promotes a selective effect upon cognition, due to the lack of investigation on visuospatial and constructive skills, language, spatial and temporal orientation. Beyond a brain neuroprotective effects, regular aerobic exercise may attenuate cognitive decline via mitigation of cerebrovascular risk factors and should be considered a respectable strategy for preventing a more severe cognitive deterioration in MCI patients. Regular participation in moderate-intensity aerobic training (which typically implies exercise sufficient to elevate heart rate or $\mathrm{Vo}_{2}$ to approximately $60 \%$ of the maximum for 50/60 minutes 3 day a week) may improve cognition. Physical exercise brings improvements in cognitive functions accompanied by structural and functional changes of brain regions in $\mathrm{MCI}$, especially as lower rates of brain atrophy and higher hippocampal efficiency (Huang et al., 2016). In this regard, aerobic exercise might modify risk factors and pathological mechanisms associated with cognitive deterioration and delay dementia onset. Measuring the effectiveness of exercise on cognition is often challenging because of intrinsic nature of MCI, in which a percentage of patients may remain stable over time or revert to a normal cognitive state. 


\begin{tabular}{|c|c|c|c|c|c|c|}
\hline & 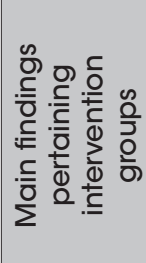 & 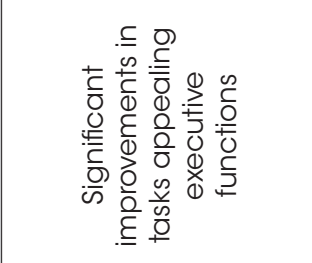 & 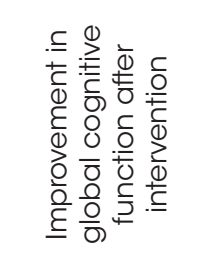 & 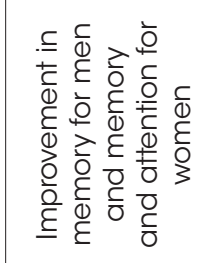 & 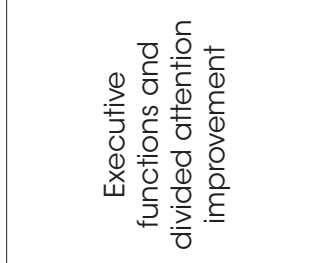 & 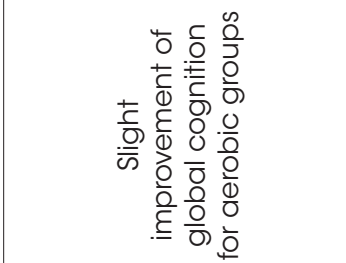 \\
\hline & $\begin{array}{l}\frac{0}{1} \\
\text { 13 } \\
\text { 은 }\end{array}$ & $\begin{array}{l}\frac{0}{0} \\
\frac{1}{2}\end{array}$ & 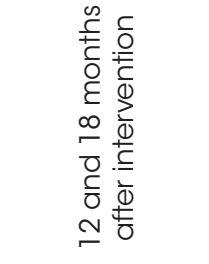 & $\begin{array}{l}0 \\
\frac{1}{0} \\
z\end{array}$ & $\begin{array}{l}\stackrel{0}{c} \\
\stackrel{2}{2}\end{array}$ & 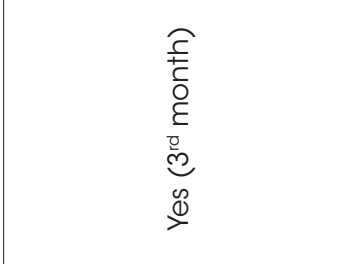 \\
\hline & 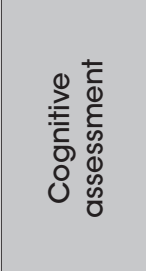 & 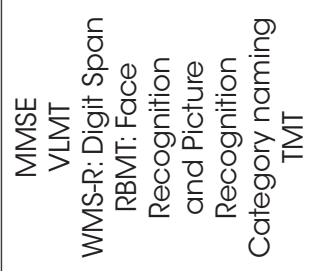 & 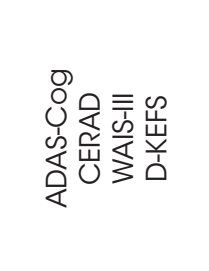 & 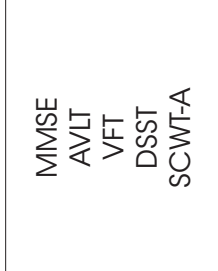 & 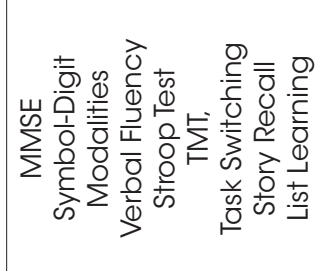 & 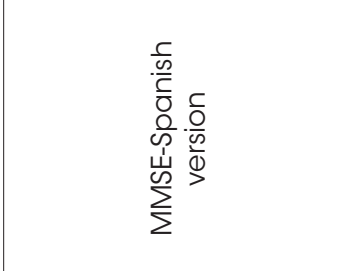 \\
\hline & $\begin{array}{l}0 \\
\frac{0}{0} \\
\frac{.0}{0} \\
0 \\
0 \\
\frac{0}{0} \\
\frac{0}{0} \\
\frac{0}{4}\end{array}$ & 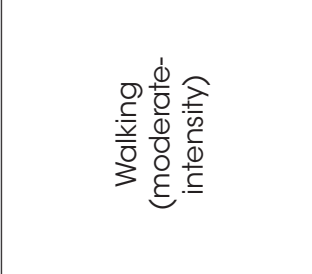 & 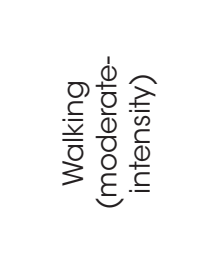 & 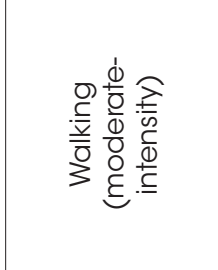 & 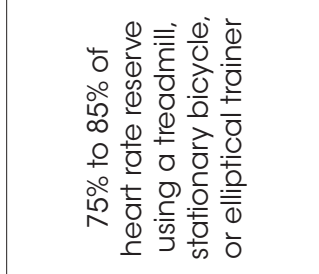 & 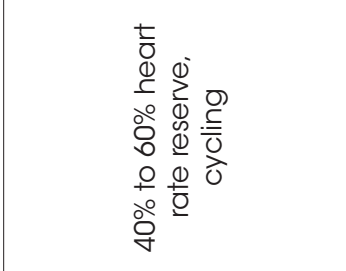 \\
\hline & 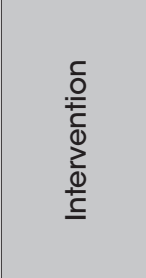 & 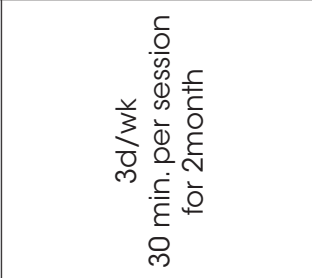 & 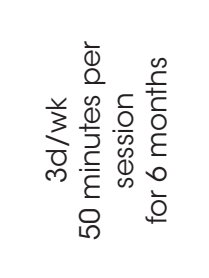 & 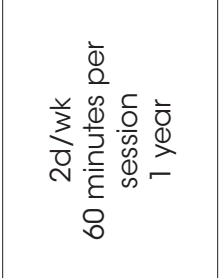 & 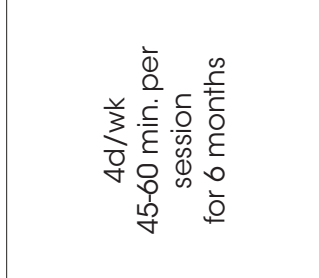 & 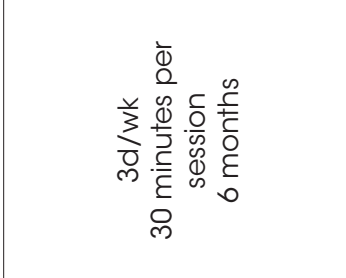 \\
\hline $\begin{array}{l}\dot{0} \\
\frac{\omega}{0} \\
\frac{2}{5} \\
0 \\
0 \\
0\end{array}$ & $\begin{array}{l}\stackrel{0}{0} \\
\frac{9}{3} \\
\frac{0}{0 !}\end{array}$ & 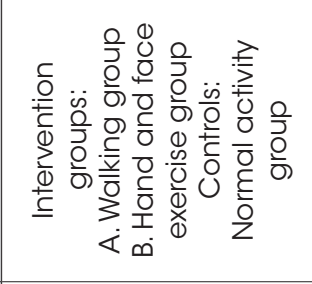 & 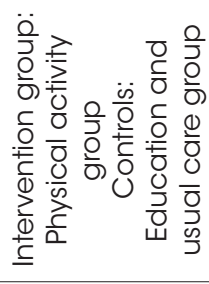 & 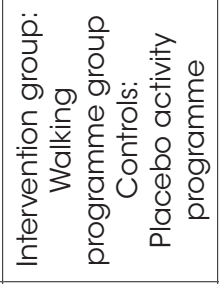 & 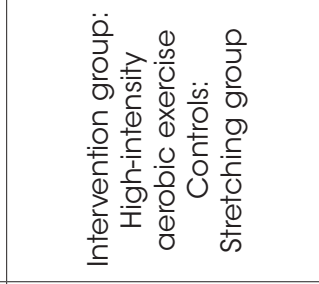 & 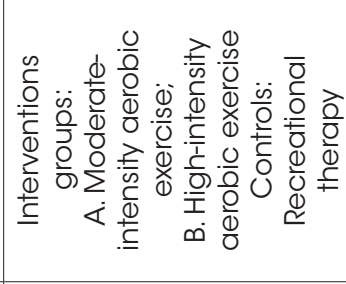 \\
\hline 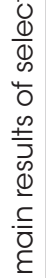 & $\begin{array}{l}\frac{0}{c} \\
\frac{0}{0} \\
\frac{0}{0} \\
\frac{0}{\bar{t}} \\
\frac{0}{0}\end{array}$ & 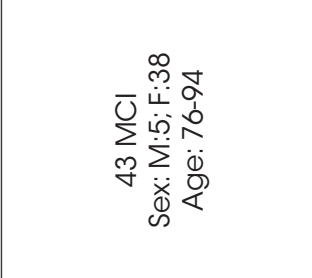 & 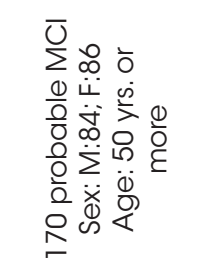 & 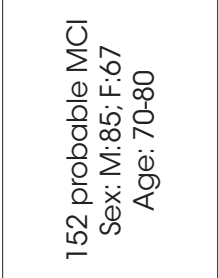 & 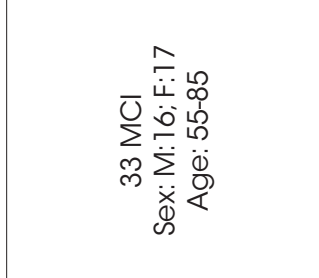 & 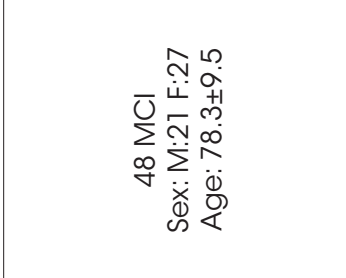 \\
\hline 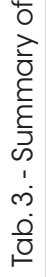 & $\frac{\overrightarrow{0}}{\frac{3}{5}}$ & 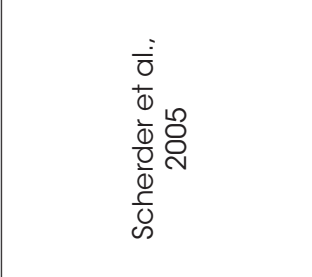 & 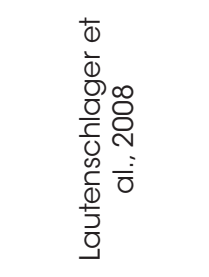 & 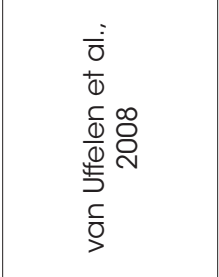 & 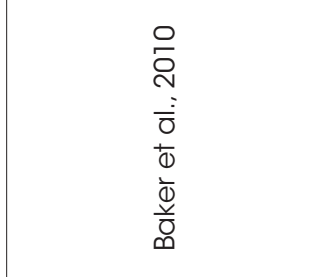 & $\begin{array}{l}\bar{\sigma} \\
\bar{\vdots} \\
\overline{0} \\
\overline{0} \\
\frac{0}{0} \\
\frac{0}{0} \\
\rho\end{array}$ \\
\hline
\end{tabular}




\begin{tabular}{|c|c|c|c|c|c|c|}
\hline \multirow{2}{*}{\multicolumn{2}{|c|}{ 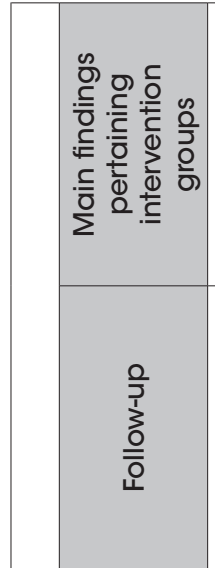 }} & 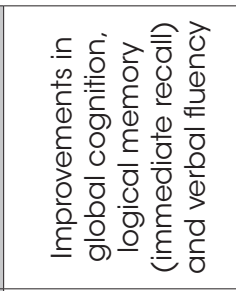 & 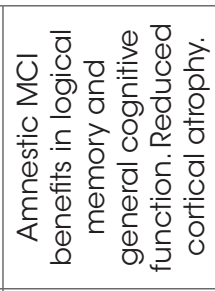 & 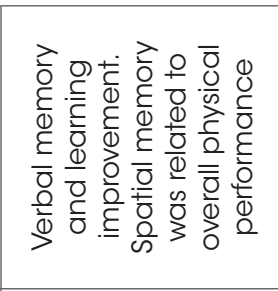 & 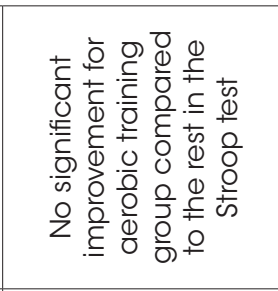 & \multirow{8}{*}{ 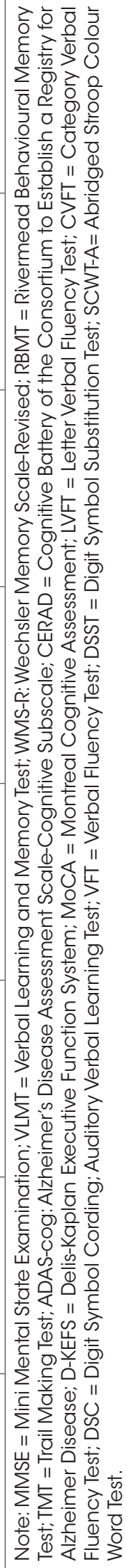 } \\
\hline & & $\begin{array}{l}0 \\
\stackrel{0}{0} \\
\text { Z }\end{array}$ & $\begin{array}{l}0 \\
\text { ¿ } \\
z\end{array}$ & 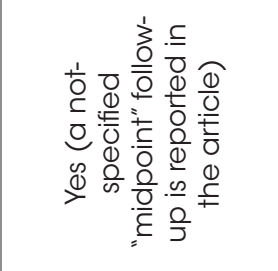 & $\begin{array}{l}0 \\
\stackrel{2}{0} \\
z\end{array}$ & \\
\hline \multirow{6}{*}{ 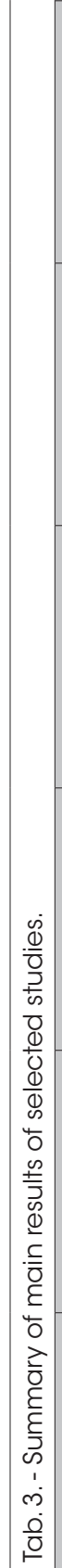 } & 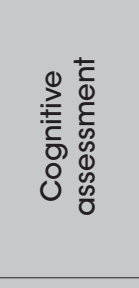 & 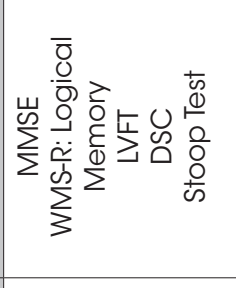 & 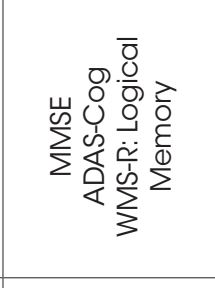 & 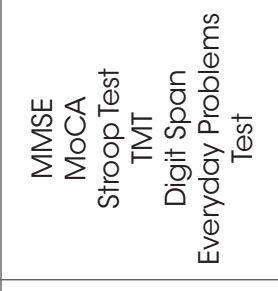 & 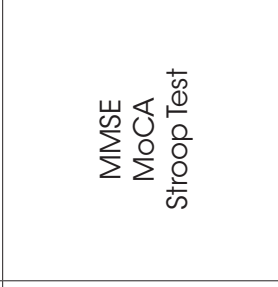 & \\
\hline & $\begin{array}{l}0 \\
\frac{0}{0} \\
\frac{0}{0} \\
\times 0 \\
0 \\
\frac{0}{0} \\
\frac{0}{0} \\
\frac{0}{0} \\
\frac{0}{4}\end{array}$ & 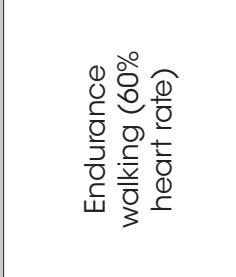 & 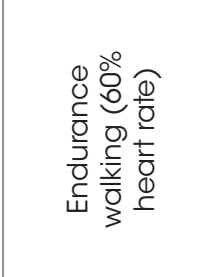 & 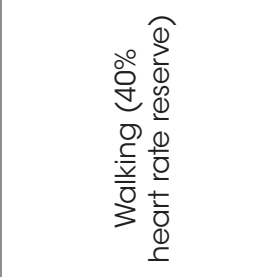 & 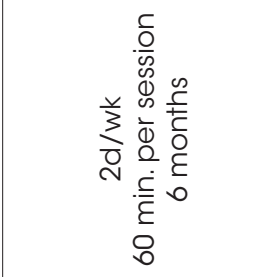 & \\
\hline & 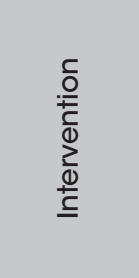 & 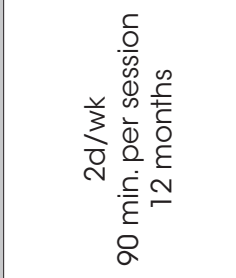 & 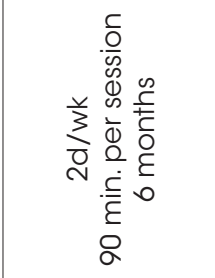 & 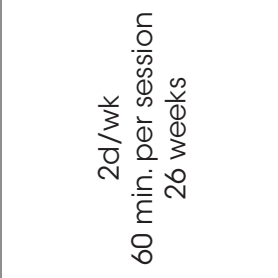 & 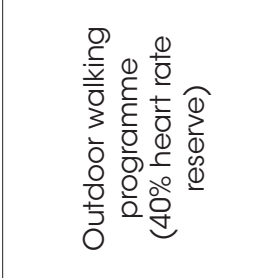 & \\
\hline & $\begin{array}{l}\frac{0}{3} \\
\frac{0}{0} \\
\frac{0}{10}\end{array}$ & 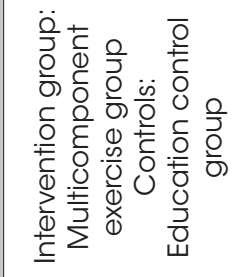 & 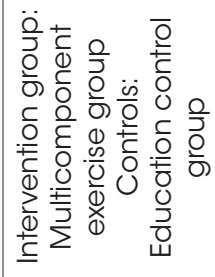 & 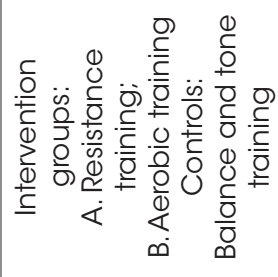 & 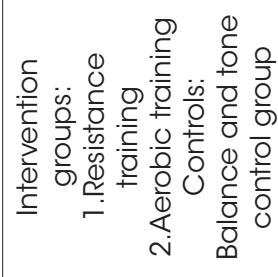 & \\
\hline & 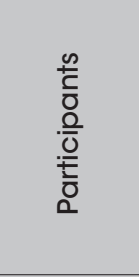 & 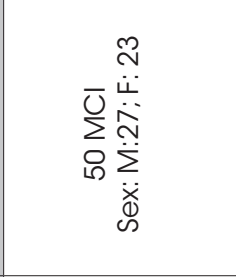 & 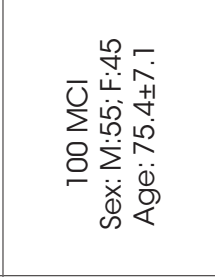 & 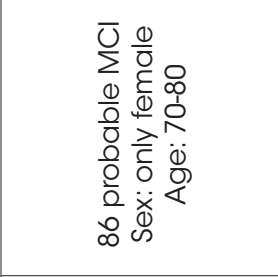 & 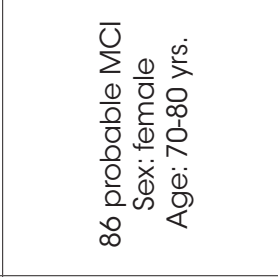 & \\
\hline & $\frac{\overrightarrow{0}}{\frac{3}{i s}}$ & 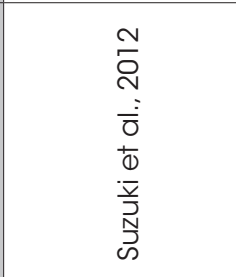 & 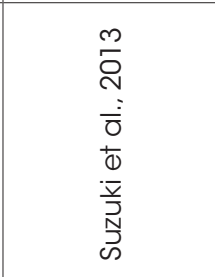 & 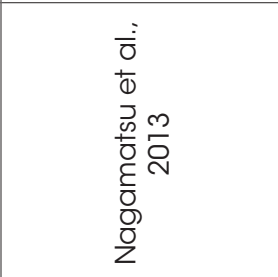 & $\begin{array}{l}m^{\infty} \\
\text { N } \\
\vdots \\
\overline{0} \\
\overline{0} \\
\frac{\infty}{2} \\
0\end{array}$ & \\
\hline
\end{tabular}


Initial findings from RCTs investigating the role of aerobic exercise upon cognition in $\mathrm{MCI}$ are quite promising. They allow to preliminary advice MCI patients, particularly those who are sedentary, to initiate daily aerobic exercise (cfr. Pruneti, 2014; Pruneti et al. 2014). Regular aerobic exercise gradually increased to achieve $60 \%$ of maximum heart rate or peak oxygen consumption per unit time $\left(\mathrm{Vo}_{2}\right)$ and performed at least 150 minutes weekly seems to be reasonable for a good regimen. This is very similar to American College of Sport Medicine and American Heart Association Recommendations reporting a "moderate-intensity aerobic physical activity for a minimum of 30 minutes on five days each week" (Nelson et al., 2007; Pruneti et al., 2011). Regular physical exercise also improves posture and reaction time, coordination and motor performance and enhances subjective well-being (Gajewsky and Falkenstein, 2016).

However, the limitations of the included studies in our review suggest to interpret results cautiously, due to several methodological problems in defining MCI, blinding, samples size, few and heterogeneous neuropsychological tests adopted to measure the effects of aerobic exercise upon cognition, changes on neurocognitive measures at follow-up (effect size strength) and their clinical significance in relation to a potential progressive cognitive deterioration.

Standardized training protocols with arms allowing the comparison among healthy elderly individuals, MCI, and early AD patients undergoing aerobic training, larger scale interventions and medium/ long-term follow-ups to evaluate maintenance effects may provide better insight into the critical role of aerobic exercise on cognitive deterioration in MCI patients. Additional research is need to address specific health care needs of MCI patients (i.e., psychoeducational interventions for patients and relatives about the importance of weekly physical exercise), cost-effectiveness of different physical trainings (i.e., aerobic trainings versus other physical trainings) and interaction with complementary interventions, such as vitamin supplementation and cognitive training.

\section{Acknowledgements}

A heartfelt thanks should be given to Sabrina Squitieri for her technical and empathic support.

\section{References}

Ahlskog J.E., Geda Y.E., Graff-Radford, N.R., Petersen, R.C. Physical exercise as a preventive or disease-modifying treatment of dementia and brain aging. Mayo Clinic Proc., 86: 876-884, 2011.

American Psychiatric Association. Diagnostic and statistical manual of mental disorders (DSM-5®). 2013, Arlington, VA: American Psychiatric Publishing.

Albert M.S., DeKosky S.T., Dickson D., Dubois B., Feldman H.H., Fox N.C., Gamst A., Holtzman D.M., Jagust W.J., Petersen R.C., Snyder P.J., Carrillo M.C., Thies B., Phelps C.H. The diagnosis of mild cognitive impairment due to Alzheimer's disease: Recommendations from the National Institute on Aging-Alzheimer's Association workgroups on diagnostic guidelines for Alzheimer's disease. Alzheimers Dement., 7: 270-279, 2011.

Baker L.D., Frank L.L., Foster-Schubert K., Green P.S., Wilkinson C.W., McTiernan, A., Plymate S.R., Fishel M.A., Watson G.S., Cholerton B.A., Duncan G.E., Mehta P.D., Craft S. Effects of aerobic exercise on mild cognitive impairment: a controlled trial. Arch. Neurol., 67: 71-79, 2010.

Bergamaschi S., Arcara G., Calza A., Villani D., Orgeta V., Mondini, S. One-year repeated cycles of cognitive training (CT) for Alzheimer's disease. Aging Clin. Exp. Res., 25: 421-426, 2013.

Cammisuli D.M., Bosinelli F., Danti S., Cipriani C. Non-pharmacological interventions for people with Alzheimer's Disease: A critical review of the scientific literature from the last ten years. Eur. Geriatr. Med., 7: 57-64, 2016.

Cammisuli D., Sportiello M.T., Danti S. Planning deficit in patients with mild cognitive impairment [Deficit delle abilità di pianificazione in pazienti affetti da mild cognitive impairment]. Giornale di Gerontologia, 61: 273-278, 2013.

Cammisuli D.M., Sportiello M.T. Cognitive psychopathology in Schizophrenia: Comparing memory performances with Obsessive-compulsive disorder patients and normal subjects on the Wechsler Memory Scale-IV. Psychiatria Danubina, 28: 118-126, 2016.

Cammisuli D., Sportiello M.T., Pinori F., Verdiani C. Role of activation therapy for patients with mild dementia or mild cognitive impairment: Caregiver burden reduction [Ruolo del programma di attivazione cognitiva per pazienti affetti da demenza lieve e soggetti con mild cognitive impairment: La riduzione del carico assistenziale a favore del caregiver]. Giornale di Gerontologia, 59: 38-45, 2011. 
Cammisuli D., Timpano Sportielo M., Danti S. Impairment of instrumental extra-memory functions in patients suffering from Mild Cognitive Impairment [Danneggiamento delle funzioni strumentali extra-mnesiche in pazienti affetti da Mild Cognitive Impairment]. Giornale di Gerontologia, 60: 255-263, 2012.

Cammisuli D.M., Timpano Sportiello M. Conscious attention defect and inhibitory control deficit in Parkinson's Disease-Mild Cognitive Impairment: A comparison study with Amnestic Mild Cognitive Impairment multiple domain. Psychiatria Danubina, in press.

Cipriani G, Cammisuli DM, Danti S, Di Fiorino, M. Disordered gambling and dementia. Eur. Geriat. Med., 7: 474-478, 2016.

Colcombe S., Kramer A.F. Fitness effects on the cognitive function of older adults a meta-analytic study. Psychol. Sci., 14: 125-130, 2003.

Davis J.C., Bryan S., Marra C.A., Sharma D., Chan A., Beattie B.L., Graf P., Liu-Ambrose, T. An economic evaluation of resistance training and aerobic training versus balance and toning exercises in older adults with mild cognitive impairment. PLoS One, 8: e63031, 2013.

De Carli C., Frisoni G.B., Clark C.M., Harvey D., Grundman M., Petersen R.C., et al. Qualitative estimates of medial temporal atrophy as a predictor of progression from mild cognitive impairment to dementia. Arch. Neurol., 64: 108-115, 2007.

Farina N., Tabet N., Rusted J. Habitual physical activity (HPA) as a factor in sustained executive function in Alzheimer-type dementia: A cohort study. Arch. Gerontol. Geriatr., 59: 91-97, 2014.

Folstein M.F., Folstein S.E., McHugh P.R. Minimental state": a practical method for grading the cognitive state of patients for the clinician. $J$. Psych. Res., 12: 189-198, 1975.

Forbes D., Thiessen E.J., Blake C.M., Forbes S.C., Forbes S. Exercise programs for people with dementia. Cochrane Database Systematic Reviews 12: CD006489, 2013.

Gates N., Singh M.A.F., Sachdev P.S., Valenzuela, M. The effect of exercise training on cognitive function in older adults with mild cognitive impairment: a meta-analysis of randomized controlled trials. Am. J. Geriatr. Psych., 21: 1086-1097, 2013.

Gajewski P.D., Falkenstein M. Physical activity and neurocognitive functioning in aging-a condensed updated review. Eur. Rev. Aging Phys. Act., 13: 1, 2016.

Geurtsen GJ, Hoogland J, Goldman JG, Schmand BA, Tröster AI, Burn D.J., Litvan I. MDS Study Group on the Validation of PD-MCI Criteria. Parkinson's disease mild cognitive impairment: application and validation of the criteria. J Parkinsons Dis., 4 : 131-137, 2014.

Hoogland J., Boel J.A., de Bie R.M.A., Geskus R.B., Schmand B.A., Dalrymple-Alford J.C., Marras C., Adler C.H., Goldman J.G., Tröster A.I., Burn D.J., Litvan I., Geurtsen G., MDS Study Group "Validation of Mild Cognitive Impairment in Parkinson Disease". Mild Cognitive Impairment as risk factor for Parkinson's disease dementia. Mov. Disord., 2017 [Epub ahead of print].

Huang P., Fang R., Li B.Y., Chen S.D. Exerciserelated changes of networks in aging and mild cognitive impairment brain. Front. Aging Neurosci., 8: 47, 2016.

Graessel E, Stemmer R, Eichenseer B, Pickel S, Donath C, Kornhuber J, Luttenberger K. Non-pharmacological, multicomponent group therapy in patients with degenerative dementia: a 12-month randomized, controlled trial. BMC Medicine, 9: 129, 2011.

Hillman C.H., Erickson K.I., Kramer A.F. Be smart, exercise your heart: exercise effects on brain and cognition. Nat. Rev. Nneurosci., 9: 58-65, 2008.

Lautenschlager N.T., Cox K.L., Flicker L., Foster J.K., van Bockxmeer F.M., Xiao J., Greenop K.R., Almeida O.P. Effect of physical activity on cognitive function in older adults at risk for Alzheimer disease: a randomized trial. JAMA, 300: 1027-1037, 2008.

Litvan I., Goldman J.G., Tröster A.I., Schmand BA, Weintraub D, Petersen RC, Aarsland D. Diagnostic criteria for mild cognitive impairment in Parkinson's disease: Movement Disorder Society Task Force guidelines. Mov. Disord., 27: 349-356, 2012.

Nagamatsu L.S., Chan A., Davis J.C., Beattie B.L., Graf P., Voss M.W., Liu-Ambrose, T. Physical activity improves verbal and spatial memory in older adults with probable mild cognitive impairment: a 6-month randomized controlled trial. J. Aging Res., 2013: 861893, 2013.

Nasreddine Z.S., Phillips N.A., Bédirian V., Charbonneau S., Whitehead V., Collin I., Chertkow H. The Montreal Cognitive Assessment, MoCA: a brief screening tool for mild cognitive impairment. J. Am. Geriatr. Soc., 53: 695-699, 2005.

Nelson M.E., Rejeski WI, Blair SN. Physical activity and public health in older adults: recommendation from the American College of Sport Medicine and the American Heart Association. Circulation, 116: 1094-1105, 2007. 
Petersen R.C., Caracciolo B., Brayne C., Gauthier S., Jelic V., Fratiglioni, L. Mild cognitive impairment: a concept in evolution. J. Intern. Med., 275: 214228, 2014.

Pruneti C.A. Positive Psychology as a forerunner of the most relevant models in Psychopathology and Psychotherapy. Psicoterapia Cognitiva $e$ Comportamentale, 20: 52-63, 2014.

Pruneti C.A., Montecucco M., Fontana F. Eating behaviour and body image in a sample of young athletes. Acta Bio Medica Atenei Parmensis, 81: 171-184, 2011.

Pruneti C., Sgromo D., Bicchieri L., Fontana F., Franceschini M., Ferraro F., Cosentino C. Contribution to the validation of Italian version of Fear-Avoidance Beliefs Questionnaire. Acta Bio Medica Atenei Parmensis, 85: 8-17, 2014.

Pruneti C., Sgromo D., Merenda J., Cammisuli D.M., Franzoni F., Galetta F., Innocenti, A. Physical Activity, Mental Exercise, and Cognitive functioning in a sample of healthy elderly males, Neurol Sci., in press.

Öhman H, Savikko N, Strandberg TE, Pitkälä K.H. Effect of physical exercise on cognitive performance in older adults with mild cognitive impairment or dementia: a systematic review. Dementia Geriat. Cogn. Dis., 38: 347-365, 2014.

Pike K.E., Savage G., Villemagne V.L., Ng S., Moss S.A., Maruff P, Rowe C.C. Beta-amyloid imaging and memory in non-demented individuals: evidence for preclinical Alzheimer's disease. Brain, 130: 2837-2844, 2007.

Rosen W.G., Mohs R.C., Davis K.L. A new rating scale for Alzheimer's disease. Am. J. Psych. 141: 1356-1364, 1984.

Scherder E.J., Van Paasschen J., Deijen J.B., Van Der Knokke S., Orlebeke J.F.K., Burgers I., Sergeant, J.A. Physical activity and executive functions in the elderly with mild cognitive impairment. Aging Mental Health, 9: 272-280, 2005.
Smith P.J., Blumenthal J.A., Hoffman B.M., Cooper H., Strauman T.A., Welsh-Bohmer K., Sherwood A. Aerobic exercise and neurocognitive performance: a meta-analytic review of randomized controlled trials. Psychosomatic Medicine, 72: 239, 2010.

Summers, M.J., Saunders, N.L. Neuropsychological measures predict decline to Alzheimer's dementia from mild cognitive impairment. Neuropsychology, 26: 498-506, 2012.

Suzuki T., Shimada H., Makizako H., Doi T., Yoshida D., Tsutsumimoto K., Park, H. Effects of multicomponent exercise on cognitive function in older adults with amnestic mild cognitive impairment: a randomized controlled trial. $B M C$ Neurology, 12: 128, 2012.

Suzuki T., Shimada H., Makizako H., Doi T., Yoshida D., Ito K., Kato, T. A randomized controlled trial of multicomponent exercise in older adults with mild cognitive impairment. PloS ONE, 8: e61483, 2013.

Thomas B.H., Ciliska D., Dobbins M., Micucci, S. A process for systematically reviewing the literature: providing the research evidence for public health nursing interventions. Worldviews on EvidenceBased Nursing, 1 (3): 176-184, 2004.

Tsolaki, M. Non pharmacological interventions for Alzheimer's disease. Neurobiol. Aging, 39: S27, 2016.

Varela S., Ayán C., Cancela J.M., Martín, V. Effects of two different intensities of aerobic exercise on elderly people with mild cognitive impairment: a randomized pilot study. Clin. Rehab., 26: 442-450, 2012.

Van Uffelen J.G., Chinapaw M.J., van Mechelen W., Hopman-Rock, M. Walking or vitamin B for cognition in older adults with mild cognitive impairment? A randomized controlled trial. Brit J. Sports Med., 42: 344-351, 2008.

Zheng G., Xia R., Zhou W., Tao J., Chen, L. Aerobic exercise ameliorates cognitive function in older adults with mild cognitive impairment: a systematic review and meta-analysis of randomised controlled trials. Brit J. Sports Med., 50: 1443-1450, 2016. 